\title{
Fatty acid profile of phospholipids and sphingomyelin in milk and regulation of sphingomyelin synthesis of mammary glands in cows receiving increasing levels of crushed sunflower seeds
}

\author{
S. Lashkari, ${ }^{1 *}$ J. W. Moller, ${ }^{1}$ S. K. Jensen, ${ }^{1}$ L. I. Hellgren, ${ }^{2} \dagger$ M. T. Sørensen, ${ }^{1}$ P. K. Theil, ${ }^{1}$ and K. Sejrsen ${ }^{1}$ \\ ${ }^{1}$ Department of Animal Science, Aarhus University, 8830 Tjele, Denmark \\ ${ }^{2}$ Department of Systems Biology, Technical University of Denmark, 2800 Lyngby, Denmark
}

\begin{abstract}
The objective of this study was to investigate the effect of increasing dietary supplementation of crushed sunflower seed (CSS) in the diet of dairy cows on the fatty acid (FA) composition of phospholipids and sphingomyelin in milk, and on mammary transcription of genes that are important for sphingomyelin de novo synthesis. Four groups of 6 cows received diets supplemented with CSS at $0 \%$ (control), or 5, 10, or $15 \%$ of dry matter for a 5 -wk experimental period. Milk samples and mammary biopsies were collected at the end of the experiment. Phospholipid concentration in milk fat decreased linearly with CSS supplementation. Sphingomyelin concentration in milk fat was unaffected by CSS supplementation. Daily yield of phospholipids decreased linearly with CSS supplementation. Daily yield of sphingomyelin was not significantly affected. The CSS supplementation linearly increased the proportion of monounsaturated FA in milk phospholipids. The major isomer incorporated into phospholipids was C18:1 (n-9 cis), which showed a linear increase with CSS supplementation. The C22:0 proportion in sphingomyelin increased linearly with CSS supplementation and constituted between 15.2 to $25.4 \%$ of total FA in sphingomyelin. However, CSS supplementation linearly decreased C23:0 sphingomyelin. Mammary transcription of serine palmitoyl transferase, long chain subunit 1 and subunit 2, the rate-limiting enzymes in ceramide synthesis, showed a linear decrease with increasing CSS supplementation. In conclusion, the data showed that dietary supplementation of CSS linearly increased the proportion of unsaturated FA and monounsaturated FA in milk phospholipids with no effect on phospholipid concentration. In addition, CSS supplementation
\end{abstract}

Received June 25, 2019.

Accepted November 19, 2019.

*Corresponding author: Saman.1@anis.au.dk

$\dagger$ Deceased. linearly decreased n-3 polyunsaturated fatty acid proportion in sphingomyelin. The results further showed that mammary transcription of important genes for sphingomyelin de novo synthesis is regulated by lipid supplementation.

Key words: mammary lipogenesis, fatty acid composition, sphingomyelin, phospholipid

\section{INTRODUCTION}

Dietary phospholipids have been shown to have several potentially health-promoting effects, including inhibition of colorectal carcinogenesis, lowering the prevalence of gastric ulceration, and decreasing intestinal absorption of cholesterol (Spitsberg, 2005; Ward et al., 2006; Lopez, 2011). The inhibitory effect on cholesterol absorption is potentially a result of a physical interaction between phospholipids and cholesterol in the intestine, which decreases cellular uptake of both components (Nyberg et al., 2000; Eckhardt et al., 2002). The interaction between cholesterol and phospholipids is dependent on the fatty acid (FA) composition of phospholipids because long-chain SFA of phospholipids have a stronger interactions with cholesterol than UFA (Lange and Steck, 2008). In accordance with this, animal experiments show that intestinal absorption of cholesterol is better inhibited by saturated phospholipids versus unsaturated phospholipids (Jiang et al., 2001) and long-chain versus medium-chain FA (Noh and Koo, 2004).

Phospholipids are present in the milk fat globule membrane (MFGM) and dairy products rich in MFGM, such as butter milk, are convenient sources of phospholipids for human nutrition (Malmsten et al., 1994). Bovine milk fat contains 0.2 to $1 \%$ of phospholipids (Kurtz, 1974) with sphingomyelin constituting approximately $20 \%$ of the phospholipids. Sphingomyelin is characterized by a high proportion of long-chain SFA (Noh and Koo, 2004; Sanchez-Juanes et al., 2009; Lopez et al., 2017), which are involved in interactions between sphingomyelin and cholesterol (Cheng et al., 
2017; Lopez et al., 2018). The strong interactions between sphingomyelin and cholesterol are considered to be fundamental for the formation of lipid rafts [i.e., sphingomyelin and cholesterol-rich sub-membrane domains in cellular membranes that are essential for cell function (Slotte, 1999)]. Lipid rafts were also found in the MFGM (Lopez et al., 2010), indicating that lipid rafts may have a biological role in the hydrolysis and absorption of milk fat in the gut of the offspring.

The FA composition of bovine milk phospholipids is dependent on breed, diet, fat globule size, and the milk fraction sampled [i.e., whole milk, cream, or MFGM (Fauquant et al., 2005; Lopez et al., 2008)]. Only a few experiments have been conducted to examine the effect of lipid supplementation on FA composition of phospholipids and the relative proportion of individual phospholipids (Palmquist and Schanbacher, 1991; Lopez et al., 2008). These authors reported that increased supplementation of UFA increased the proportion of UFA in milk phospholipids. However, neither the composition of milk sphingomyelin nor mammary transcription of genes involved in sphingomyelin de novo synthesis have been investigated in cows receiving lipid supplements. Given the specific role of sphingomyelin in cellular membranes and their tentative role in the MFGM, it is likely that the FA composition of sphingomyelin in bovine milk is more strictly regulated than that of phospholipids. A strict regulation of the FA composition may have role in transcriptional regulation of enzymes involved in sphingomyelin de novo synthesis, which is mediated by the coordinated action of the several enzymes. Serine palmitoyl transferase, long chain subunit 1 (SPTLC1) and subunit 2 (SPTLC2), and longevity assurance gene 1 homolog/ceramid synthase 2 (LASS2) are involved in the synthesis of ceramide, the backbone of sphingomyelin, and sphingomyelin synthase 2 (SGMS2) mediates the phospho-choline transfer to ceramide, ultimately producing sphingomyelin. The UDP-glucose ceramide glycosyltransferase ( $U G C G)$ mediates the formation of glycosphingolipids from ceramide, and is an alternative endpoint to sphingomyelin for ceramides. It has been reported that SPTLC1 and SPTLC2, rate-limiting factors in sphingomyelin synthesis, are regulated transcriptionally and post-transcriptionally (Hanada, 2003); however, no data have been reported on the regulatory mechanism of LASS2, SGMS2, and UGCG. The objective of this study was to examine the effect of incremental supplement of CSS to dairy cows on the FA composition of phospholipids and in particular sphingomyelin, and the mammary transcription of genes involved in sphingomyelin de novo synthesis.

\section{MATERIALS AND METHODS}

All procedures were approved by the Danish Animal Experiment Inspectorate and complied with the Danish Ministry of Justice Law no. 1306 and 612 concerning animal experimentation and care of experimental animals (Dyreforsøgsloven).

\section{Experimental Design and Sampling}

Twenty-four healthy lactating Holstein Friesian cows $(186 \pm 20$ DIM, yield: $25.3 \pm 2.5 \mathrm{~kg} / \mathrm{d})$ from the dairy herd at Aarhus University were included in the experiment. In a 1-wk pre-experimental period, they were fed a basal diet (similar to control). On the last day of the pre-experimental period, milk yield was recorded and milk samples analyzed for fat. Cows were blocked according to days in milk within parity, and randomly allocated to 1 of 4 diets for a 5-wk experimental period. Cows were fed either a diet without lipid supplement (control) or diets supplemented with crushed sunflower seed (CSS) at 5, 10, or 15\% of DM as a source of UFA. Diet composition is shown in Table 1. To maintain normal rumen $\mathrm{pH}$ and function, CSS was not accompanied by linear changes in other ingredients at the $15 \%$ CSS level. The decreased inclusion of mineral mix especially at $15 \%$ CSS occurs because sunflower contain more minerals than barley. Milk samples and mammary biopsies were obtained at the end of the experiment,

Table 1. Composition of control diet and diets with supplementation of crushed sunflower seeds (CSS; \% of $\mathrm{DM})$

\begin{tabular}{lcccc}
\hline & \multicolumn{3}{c}{ Diet } \\
\cline { 2 - 5 } Feedstuff & Control & $5 \%$ CSS & $10 \%$ CSS & $15 \%$ CSS \\
\hline CSS & - & 5.1 & 10.3 & 15.7 \\
Soybean meal & 14.3 & 10.5 & 8.8 & 13.4 \\
Barley & 29.8 & 28.5 & 24.6 & 12.6 \\
Grass clover silage & 55.3 & 55.3 & 55.8 & 58.1 \\
Mineral mixture & 0.28 & 0.28 & 0.17 & - \\
Limestone & 0.33 & 0.33 & 0.33 & 0.28 \\
\hline
\end{tabular}


and milk from 2 consecutive milkings were pooled and stored at $-20^{\circ} \mathrm{C}$ until lipid analyses.

\section{Extraction and Analysis of Phospholipids and Sphingomyelin}

Di-nonadecyl-phosphatidyl-choline (C19:0 PC) and C17:0 were added as internal standards to milk samples before lipid extraction. Lipids were extracted from milk using the method described by Jensen (2008). Phospholipids were isolated from nonpolar lipids on aminopropyl cartridges (Strata NH2, Phenomenex, Værløse, Denmark) using a slightly modified version of the method of Kaluzny et al. (1985). The cartridges were conditioned in $400 \mu \mathrm{L}$ of hexane before applying the samples in $200 \mu \mathrm{L}$ of $\mathrm{CHCl}_{3}$. Neutral lipids were eluted with $4 \mathrm{~mL}$ of $\mathrm{CHCl}_{3}: 2$-propanol $(2: 1)$, which was followed by elution of FFA with $5 \mathrm{~mL}$ of $2 \%$ acetic acid in diethylether. Finally, the phospholipids were eluted with $4 \mathrm{~mL}$ of $\mathrm{MeOH}$ into a new glass. Thirty percent of the phospholipid fraction was trans-methylated and analyzed on a GC-flame ionization detector, as described earlier (Werner et al., 2011). In the remaining part of the phospholipid fraction, glycerophospholipids were hydrolyzed by mild alkaline hydrolysis (Jenkins and Hannun, 1999). The sphingomyelin was isolated from the hydrolysate by repeating the aminopropyl-cartridge fractionation, as described above. Hereafter, sphingomyelin was hydrolyzed as described by Aveldano and Horrocks (1983) and FAME was produced from the released FA using the bruno trifluoride $\left(\mathrm{BF}_{3}\right)$-catalyzed procedure described by Werner et al. (2011).

\section{Mammary Biopsies}

On the last day of experiment (d 28) and after milking, the left front quarter of the udder was shaved, and an incision site without visual blood vessels was localized and anaesthetized subcutaneously with $2 \mathrm{~mL}$ of Xylocain $(20 \mathrm{mg} / \mathrm{mL}$ lidocaine, AstraZeneca, Albertslund, Denmark) and cleaned with Hibitane (70\% alcohol solution 1:10, Sigma-Aldrich, St. Louis, MO). Biopsies were taken with an automatic biopsy instrument (Manan Pro-Mag 2.2, Manan Medical Products Inc., Wheeling, IL) loaded with a 14 gauge $\times 10 \mathrm{~cm}$ needle (Manan ACN II, Manan Medical Products Inc.). Approximately $20 \mathrm{mg}$ of tissue was collected per sampling, and a maximum of 2 samples was taken per cow. Tissue was snap frozen in liquid nitrogen and stored in Cryotubes (Nunc GmbH \& Co. KG, Langenselbold, Germany) at $-80^{\circ} \mathrm{C}$ until further analysis as described by Sorensen et al. (2006).

\section{Real-Time PCR}

The relative mRNA abundance was determined according to Sorensen et al. (2006) by quantitative PCR using gene-specific primers (DNA Technology, Aarhus, Denmark) and various commercial chemicals to detect mRNA abundance (using either locked nucleic acid fluorescent probes from Exiqon, Værum, Denmark, or fluorescent TaqMan probes purchased from Applied Biosystems, Nærum, Denmark) were used. Fold change was calculated using the $2^{-\Delta \Delta \mathrm{Ct}}$ method under consideration of PCR efficiency for each assay. Cycle threshold (Ct) is the number of PCR cycles required for the fluorescent signal to cross the threshold (i.e., exceeds background level). Three endogenous controls [glyceraldehyde 3-phosphate dehydrogenase $(G A P D H)$, ubiquitously expressed transcript $(U X T)$, and beta actin $(A C T B)]$ were tested by normalizing against the RNA content and all were found to be suitable housekeeping genes as they were not affected by the diets $(P=0.49$, $P=0.93$, and $P=0.84$, respectively). Thus, the mean $\mathrm{Ct}$ of the 3 housekeeping genes were subsequently used to normalize all target genes. All samples were analyzed in duplicates for each gene except for endogenous control genes, which were analyzed in triplicates. Primer and probe sequences are listed in Table 2. No signal was detected in samples of pure water or bovine DNA.

\section{Statistical Analysis}

Statistical analysis was performed in SAS software (version 9.4, SAS Institute Inc., Cary, NC). The statistical model was a general linear model:

$$
Y_{i j k}=\mu+T_{i}+B_{j}+E_{i j k},
$$

where $Y_{i j k}$ is the dependent variable, $\mu$ is the overall mean, and the model includes the fixed effects of treatment $\left(T_{i}\right)$ and random effects of block $\left(B_{j}\right)$, and $E_{i j k}$ is the random error. In analysis of production data, the model further included pre-experimental production data as covariates. A polynomial contrast analysis was employed to test for linear, quadratic, and cubic effects. The polynomial contrasts should be interpreted with caution because the linear inclusion of CSS was not accompanied by linear changes in other ingredients at the 15\% CSS level. All statistics on mRNA abundance were performed at the $\Delta \mathrm{Ct}$ level, whereas the relative mRNA abundance (mean, lower and upper 95\% CI) was calculated using the $2^{-\Delta \Delta \mathrm{Ct}}$ transformation. Significance was declared at $P<0.05$. 


\section{RESULTS}

\section{DMI and Milk Yield}

Dry matter intake was $18.4,17.3,14.5$, and $14.8 \mathrm{~kg} / \mathrm{d}$ in control and 5, 10, and 15\% CSS, respectively, and was decreased linearly $(P<0.01)$ with supplementation of CSS. As well, daily milk yield was decreased linearly $(P<0.01)$ with CSS supplementation (i.e., 29.0, 27.6, 20.9 , and $20.9 \mathrm{~kg} / \mathrm{d}$ for control and 5,10 , and $15 \%$ CSS, respectively). The proportion of UFA in milk was 27.5 , $32.5,40.2$, and 40.30 (g/100 g of milk FA) in control and 5, 10, and $15 \%$ CSS, respectively, and increased linearly $(P<0.01)$ with CSS supplementation.

\section{Phospholipid and Sphingomyelin Yield and Concentration}

Milk fat concentration increased linearly with CSS supplementation $(P<0.01$; Table 3$)$. Phospholipid yield decreased linearly due to a decrease in milk yield $(P<0.01)$. Sphingomyelin concentration increased linearly with CSS supplementation $(P=0.04)$, whereas sphingomyelin yield was not significantly affected $(P$ $=0.06)$. Concentration of phospholipid in milk fat linearly decreased with increasing CSS supplementation $(P<0.01)$. However, concentration of sphingomyelin in milk fat was not affected. Proportion of sphingomyelin in phospholipids linearly increased with CSS supplementation $(P<0.01)$.

\section{FA Composition of Phospholipids}

Proportion of C16:0 incorporated in phospholipids decreased linearly with CSS supplementation $(P<$ 0.01; Table 4). Proportion of MUFA in phospholipids was increased linearly by CSS supplementation $(P<$ 0.01). The major FA contributing to the increase was C18:1 (n-9 cis), which increased linearly in response to CSS supplementation $(P<0.01)$, but C20:1 (n-9 cis; $P<0.01$ ), C18:1 (n-9 trans; $P<0.01$ ), and C18:1 (trans-11; $P<0.01$ ) also increased linearly. Although C18:0 proportion in phospholipids showed a quadratic effect with CSS supplementation $(P=0.03)$, the proportion of SFA in phospholipids decreased linearly $(P$ $<0.01)$. The linear decrease in SFA caused a linear decreased proportion of $\mathrm{C} 16: 0, \mathrm{C} 15: 0, \mathrm{C} 14: 0$, and C12:0 $(P<0.01)$. The proportion of C18:2 (n-6 cis) showed a cubic effect with CSS supplementation $(P=0.04)$.

\section{FA Composition of Sphingomyelin}

Proportion of C23:0 in sphingomyelin was decreased linearly by CSS supplementation $(P<0.01$; Table $5)$. The $\mathrm{C} 22: 0$ proportion in sphingomyelin showed a quadratic effect with CSS supplementation $(P=0.03)$.

Table 2. Primer and probe design used for real-time PCR

\begin{tabular}{|c|c|c|}
\hline Gene $^{1}$ & Primer/probe & Sequence $\left(5^{\prime}\right.$ to $\left.3^{\prime}\right)$ \\
\hline \multirow[t]{3}{*}{$L A S S 2$} & Forward & TCATGGCTCTGCACGACTCT \\
\hline & Reverse & CCATCCCGCGTAGTTAAACATC \\
\hline & Probe & TACCTGCTAGAGTCAGCCA \\
\hline \multirow[t]{3}{*}{$S P T L C 1$} & Forward & GGAACTTGTGGACCTAGAGGATTTT \\
\hline & Reverse & TGCCAGGCGGTCTTCTAAA \\
\hline & Probe & CACATTTGATGTGCACTTG \\
\hline \multirow[t]{3}{*}{ SPTLC2 } & Forward & CTTGTTAGCAAAGGTTGCCTGATT \\
\hline & Reverse & GGCTCCCAGAACCAGTGAAG \\
\hline & Probe & TGAGTGATGAACTGAACC \\
\hline \multirow[t]{3}{*}{ SGMS2 } & Forward & CCGGTGCCTGGAATGC \\
\hline & Reverse & AGCCGTAGAATCCGCTGTACTT \\
\hline & Probe & TGCTCCAAAGCTC \\
\hline \multirow[t]{3}{*}{$U G C G$} & Forward & CAGAATGATCAGGTGGACCAAA \\
\hline & Reverse & TGGCTCGCAAATTATTGTAGCA \\
\hline & Probe & TGCGAATTAACATGCTTC \\
\hline \multirow[t]{3}{*}{$A C T B$} & Forward & ACCCAGATCATGTTCGAGACCTT \\
\hline & Reverse & CTGTATGCCTCTGGCCGCACCA \\
\hline & Probe & TCACCGGAGTCCATCACGAT \\
\hline \multirow[t]{3}{*}{$G A P D H$} & Forward & GTCGGAGTGAACGGATTTGG \\
\hline & Reverse & CAATGTCCACTTTGCCAGAGTTAA \\
\hline & Probe & CGCCTGGTCACCAGGGCTGCT \\
\hline \multirow[t]{3}{*}{$U X T$} & Forward & GATTTGGGCTGTAACTTCTTCGTT \\
\hline & Reverse & GGGCCACATAGATCCGTGAA \\
\hline & Probe & ACACAGTGGTCCCAGACA \\
\hline
\end{tabular}

${ }^{1}$ Longevity assurance gene 1 homolog (LASS2), serine-palmitoyl transferase, long chain subunit 1 (SPTLC1), serine-palmitoyl transferase, long chain subunit 2 (SPTLC2), sphingomyelin synthase 2 (SGMS2), UDPglucose ceramide glucosyltransferase $(U G C G)$, beta actin $(A C T B)$, glyceraldehyde 3-phosphate $(G A P D H)$, ubiquitously expressed transcript $(U X T)$. 
Table 3. Concentration and yield of phospholipids and sphingomyelin in milk from cows fed diets with increasing levels of crushed sunflower seeds (CSS)

\begin{tabular}{|c|c|c|c|c|c|c|c|c|}
\hline \multirow[b]{2}{*}{ Item } & \multicolumn{4}{|c|}{ Treatment $^{1}$} & \multirow[b]{2}{*}{ SEM } & \multicolumn{3}{|c|}{$P$-value for polynomial contrast } \\
\hline & Control & $5 \% \mathrm{CSS}$ & $10 \% \mathrm{CSS}$ & $15 \% \mathrm{CSS}$ & & Linear & Quadratic & Cubic \\
\hline Phospholipids, $\%$ of milk fat & 1.47 & 1.53 & 1.02 & 0.93 & 0.07 & $<0.01$ & 0.07 & 0.81 \\
\hline Sphingomyelin, $\%$ of milk fat & 0.59 & 0.58 & 0.56 & 0.49 & 0.49 & 0.13 & 0.58 & 0.98 \\
\hline Phospholipid concentration, g/L & 0.49 & 0.43 & 0.49 & 0.43 & 0.02 & 0.06 & 0.06 & 0.56 \\
\hline Phospholipid yield, g/d & 13.4 & 11.8 & 9.2 & 8.7 & 0.5 & $<0.01$ & 0.16 & 0.13 \\
\hline Sphingomyelin in phospholipids, \% & 41.1 & 50.9 & 56.3 & 53.4 & 3.3 & 0.01 & 0.07 & 0.81 \\
\hline
\end{tabular}

${ }^{1}$ Cows were fed a diet without lipid supplement (control) or diets supplemented with CSS at 5, 10, or $15 \%$ of DM.

Both C22:2 (n-6 cis) and C20:5 (n-3 cis) in sphingomyelin decreased linearly with the inclusion of CSS supplement. The SFA proportion in sphingomyelin showed a cubic effect with CSS supplementation $(P<0.01)$.

\section{Mammary Transcription of Sphingolipogenic Genes}

The SPTLC1 mRNA decreased linearly $(P=$ 0.03) with CSS supplementation (Table 6). Similarly,

Table 4. Proportion of fatty acids (FA) in phospholipids (g of FA/100 g of FA of phospholipids) of milk from cows fed diets with increasing levels of crushed sunflower seeds (CSS)

\begin{tabular}{|c|c|c|c|c|c|c|c|c|}
\hline \multirow[b]{2}{*}{ Fatty acid } & \multicolumn{4}{|c|}{ Treatment $^{1}$} & \multirow[b]{2}{*}{ SEM } & \multicolumn{3}{|c|}{$P$-value for polynomial contrast } \\
\hline & Control & $5 \% \mathrm{CSS}$ & $10 \% \mathrm{CSS}$ & $15 \% \mathrm{CSS}$ & & Linear & Quadratic & Cubic \\
\hline $\mathrm{C} 12: 0$ & 0.38 & 0.30 & 0.066 & $\mathrm{ND}^{2}$ & 0.05 & $<0.01$ & 0.92 & 0.25 \\
\hline C13:0 & 0.10 & 0.17 & 0.12 & 0.11 & 0.03 & 0.94 & 0.55 & 0.46 \\
\hline C14:0 & 4.38 & 4.00 & 0.81 & 0.46 & 0.45 & $<0.01$ & 0.93 & 0.03 \\
\hline C15:0 & 1.02 & 0.88 & 0.35 & 0.25 & 0.08 & $<0.01$ & 0.85 & 0.06 \\
\hline $\mathrm{C} 16: 0$ & 24.7 & 21.4 & 14.4 & 13.0 & 1.1 & $<0.01$ & 0.23 & 0.01 \\
\hline C16:1 (n-9 cis) & 1.12 & 0.83 & 0.39 & 0.33 & 0.08 & $<0.01$ & 0.09 & 0.10 \\
\hline $\mathrm{C} 17: 0$ & 0.75 & 0.66 & 0.62 & 0.60 & 0.02 & $<0.01$ & 0.12 & 0.71 \\
\hline $\mathrm{C} 17: 1$ (n-9 cis) & 1.77 & 0.31 & 0.89 & 0.45 & 0.26 & 0.19 & 0.41 & 0.21 \\
\hline C18:0 & 18.3 & 21.5 & 25.9 & 25.1 & 0.8 & $<0.01$ & 0.03 & 0.11 \\
\hline C18:1 (trans-11) & 0.53 & 1.03 & 1.69 & 1.95 & 0.04 & $<0.01$ & 0.48 & 0.70 \\
\hline $\mathrm{C} 18: 1$ (n-9 cis) & 30.1 & 33.7 & 38.5 & 38.4 & 1.0 & $<0.01$ & 0.40 & 0.66 \\
\hline C18:1 (n-9 trans) & 0.32 & 0.45 & 0.51 & 0.69 & 0.04 & $<0.01$ & 0.74 & 0.51 \\
\hline $\mathrm{C} 18: 1$ (n-7 cis) & 0.70 & 0.62 & 0.65 & 0.60 & 0.14 & 0.59 & 0.87 & 0.49 \\
\hline $\mathrm{C} 18: 2$ (n-6 cis) & 7.93 & 9.15 & 8.05 & 8.86 & 0.24 & 0.42 & 0.73 & 0.04 \\
\hline $\mathrm{C} 18: 3(\mathrm{n}-3$ cis $)$ & 0.93 & 0.74 & 0.51 & 0.50 & 0.04 & $<0.01$ & 0.03 & 0.13 \\
\hline $\mathrm{C} 20: 0$ and $\mathrm{C} 18: 3$ (n-6 cis $)^{3}$ & 0.22 & 0.26 & 0.27 & 0.28 & 0.01 & 0.22 & 0.23 & 0.58 \\
\hline $\mathrm{C} 20: 1$ (n-9 cis) & 0.65 & 1.06 & 1.57 & 2.38 & 0.18 & $<0.01$ & 0.38 & 0.80 \\
\hline $\mathrm{C} 20: 3$ (n-6 cis) & 1.90 & 0.73 & 1.44 & 1.04 & 0.18 & 0.32 & 0.38 & 0.14 \\
\hline $\mathrm{C} 20: 4(\mathrm{n}-3 \mathrm{cis})$ & 0.22 & 0.27 & 0.76 & 0.59 & 0.04 & 0.10 & 0.38 & 0.15 \\
\hline $\mathrm{C} 20: 4$ (n-6 cis) & 0.89 & 0.79 & 0.59 & 0.76 & 0.07 & 0.30 & 0.26 & 0.36 \\
\hline $\mathrm{C} 20: 5$ (n-3 cis) & 0.39 & 0.29 & 0.18 & 0.29 & 0.03 & $<0.01$ & $<0.01$ & $<0.01$ \\
\hline $\mathrm{C} 22: 0$ & ND & ND & 0.18 & 0.20 & 0.05 & 0.07 & 0.93 & 0.41 \\
\hline $\mathrm{C} 22: 5$ (n-3 cis) & 0.49 & 0.52 & 0.51 & 0.51 & 0.03 & 0.85 & 0.84 & 0.77 \\
\hline $\mathrm{C} 22: 5$ (n-6 cis) & 0.29 & $<0.01$ & 0.88 & 1.97 & 0.25 & $<0.01$ & 0.06 & 0.55 \\
\hline $\mathrm{C} 23: 0$ & 1.00 & $<0.01$ & 0.17 & $<0.01$ & 0.17 & 0.05 & 0.21 & 0.25 \\
\hline $\mathrm{C} 24: 0$ & 0.61 & 0.12 & 0.41 & 0.32 & 0.09 & 0.54 & 0.38 & 0.21 \\
\hline MUFA & 35.4 & 38.6 & 44.2 & 45.0 & 1.1 & $<0.01$ & 0.64 & 0.33 \\
\hline$n-3$ & 1.85 & 1.56 & 1.72 & 1.33 & 0.08 & 0.20 & 0.24 & 0.46 \\
\hline$n-6$ & 11.0 & 10.7 & 10.9 & 12.7 & 0.4 & 0.14 & 0.16 & 0.76 \\
\hline PUFA & 12.8 & 12.5 & 12.7 & 13.9 & 1.0 & 0.40 & 0.27 & 0.93 \\
\hline SFA & 51.3 & 49.1 & 44.8 & 40.1 & 1.1 & $<0.01$ & 0.72 & 0.28 \\
\hline UFA & 48.7 & 50.9 & 57.1 & 59.8 & 1.3 & $<0.01$ & 0.72 & 0.28 \\
\hline
\end{tabular}

${ }^{1}$ Cows were fed a diet without lipid supplement (control) or diets supplemented with CSS at 5, 10, or 15\% of DM.

${ }^{2} \mathrm{ND}=$ not detected.

${ }^{3}$ Coeluting peaks were present between $\mathrm{C} 20: 0$ and $\mathrm{C} 18: 3$ (n-6 cis). 
Table 5. Proportion of fatty acid (FA) in sphingomyelin (g of FA/100 g of FA of sphingomyelin) of milk from cows fed diets with increasing levels of crushed sunflower seeds (CSS)

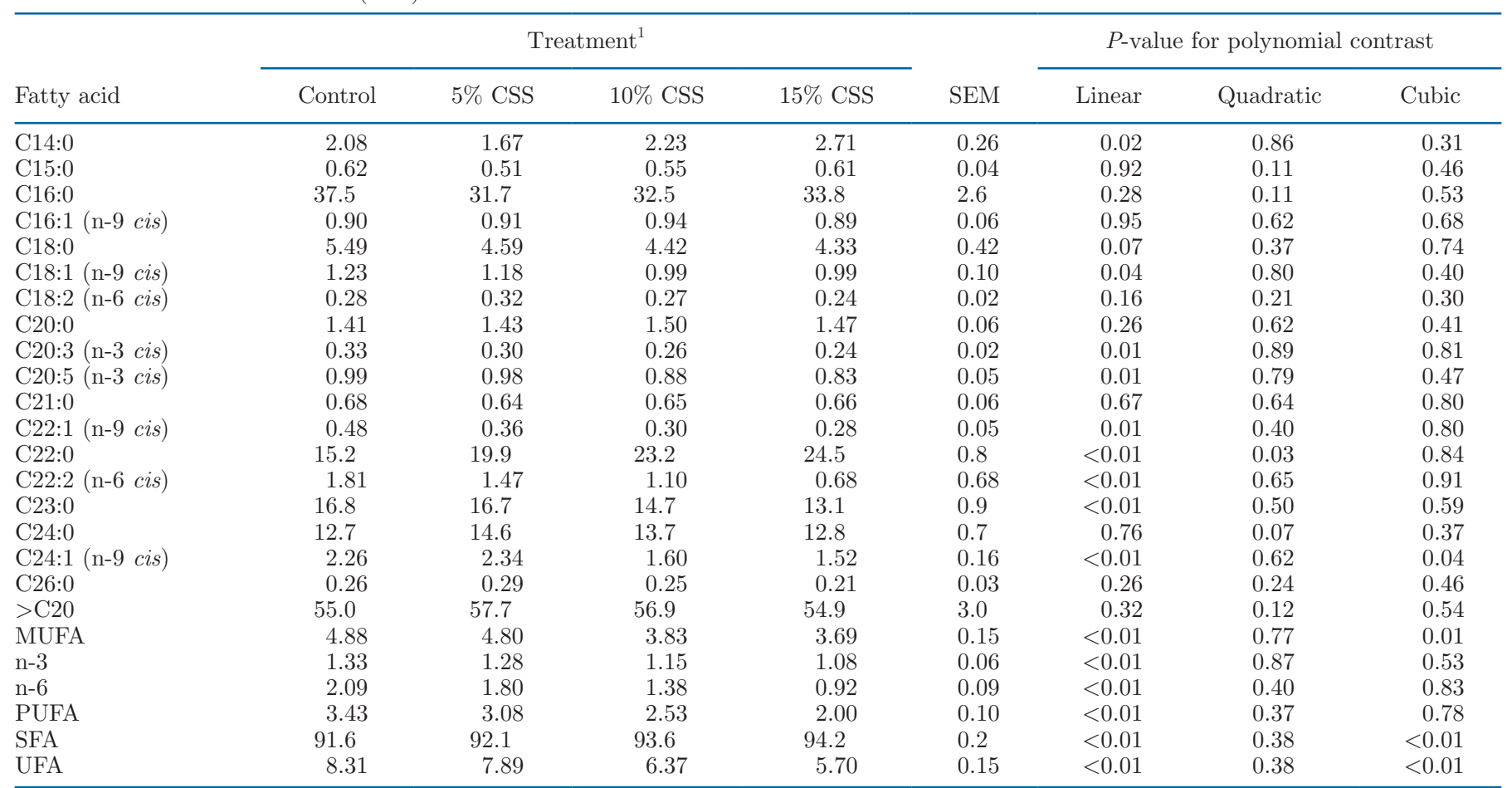

${ }^{1}$ Cows were fed a diet without lipid supplement (control) or diets supplemented with CSS at 5, 10, or $15 \%$ of DM.

SPTLC2 mRNA showed a linear decrease $(P=0.02)$ with CSS supplementation.

\section{DISCUSSION}

Sphingolipids have a unique structure and FA composition that favor strong interaction with cholesterol in cell membranes. Sphingolipids are synthesized via a unique pathway, and FA incorporated into sphingolipids share no pathway intermediates with triglycerides or phospholipids. In contrast, triglycerides and phospholipids are derived from diglycerides, and their FA composition is similar (Bitman and Wood, 1990). The effect of lipid supplementation on the FA composition of phospholipids and sphingomyelin reflects the different synthesis pathways of lipid fractions.

\section{Phospholipid and Sphingomyelin Yield and Concentration}

Concentration of phospholipids determined in the present study (i.e., 0.93 to 1.47) was higher than the results found in cows fed linseed diets (Lopez et al., 2008). However, sphingomyelin concentration was lower than sphingomyelin concentration reported by Lopez et al. (2008). These discrepancies may be due to dif-

Table 6. Mammary transcription genes of sphingomyelin biosynthesis in cows fed diets with increasing levels of crushed sunflower seed (CSS)

\begin{tabular}{|c|c|c|c|c|c|c|c|}
\hline Gene $^{1}$ & \multicolumn{4}{|c|}{ Treatment $^{2}$} & \multicolumn{3}{|c|}{$P$-value for polynomial contrast } \\
\hline LASS2 & $1.00(0.80-1.25)^{3}$ & $0.89(0.72-1.20)$ & $0.80(0.67-1.05)$ & $0.81(0.57-0.95)$ & 0.08 & 0.85 & 0.95 \\
\hline SPTLC1 & $1.00(0.71-1.41)$ & $0.89(0.59-1.27)$ & $0.77(0.58-1.14)$ & $0.70(1.37-0.80)$ & 0.03 & 0.45 & 0.72 \\
\hline SPTLC2 & $1.00(0.77-1.30)$ & $1.08(0.79-1.41)$ & $0.71(0.60-1.02)$ & $0.62(0.48-0.87)$ & 0.02 & 0.27 & 0.33 \\
\hline$U G C G$ & $1.00(0.73-1.37)$ & $1.48(0.87-1.80)$ & $1.48(1.06-1.96)$ & $1.41(0.96-1.89)$ & 0.37 & 0.39 & 0.71 \\
\hline
\end{tabular}

${ }^{1} L A S S 2=$ longevity assurance gene 1 homolog; SPTLC1 = serine-palmitoyl transferase, long chain subunit $1 ; S P T L C 2=$ serine-palmitoyl transferase, long chain subunit 2;SGMS2 = sphingomyelin synthase 2; UGCG = UDP-glucose ceramide glucosyltransferase.

${ }^{2}$ Cows were fed a diet without lipid supplement (control) or diets supplemented with CSS at 5, 10, or $15 \%$ of DM.

${ }^{3} 95 \%$ CI (lower limit-upper limit). 
ferences in the stage of lactation, feeding of the cow, milk, and the methods of preparation and analysis of the samples. The results showed that concentration of milk phospholipids was decreased linearly by CSS supplementation. This is probably due to a lower surface area of smaller milk fat globules (Lopez et al., 2008). In the present study, the proportion of sphingomyelin in phospholipids increased and was accompanied by decreased concentration of phospholipids in milk fat, most likely to maintain rigidity of MFGM (Lopez et al., 2008, 2011), which has been discussed below.

\section{FA Composition of Phospholipids}

Our results show that the FA composition of milk phospholipids is responsive to dietary changes. In our experiment, CSS supplementation linearly decreased the phospholipid proportion of $\mathrm{C} 16: 0$ by up to 12 percentage points, depending on the level of supplementation. The major FA substituting C16:0 in milk phospholipids are C18:0 and C18:1 (n-9, cis). In the present experiment, C18:0 in milk phospholipids increased by approximately 7 percentage points, which is in agreement with the proportion of C18:0 in milk phospholipids of cows fed linseeds (Lopez et al., 2008). However, in our experiment, C18:0 constituted between 18.3 and $25 \%$ of the total FA present in milk phospholipids, whereas Lopez et al. (2008) reported a C18:0 proportion between 10.1 and $17.3 \%$. Also, the level of C18:1 (n-9, cis) in our experiment (range: 30 to $38 \%$ ) is higher than that reported by Lopez et al. (2008). However, the variation in phospholipid proportion of FA is large, and the variation observed in the present experiment is in agreement with previous reports (Fong et al., 2007; Lopez et al., 2014).

Although in the present study, diet concentration of C18:2 (n-6 cis) increased with increasing CSS supplementation, a cubic effect of CSS supplement on C18:2 (n-6 cis) proportion of phospholipids was observed. These findings might reflect the limited influence of CSS levels on the FA composition of milk phospholipids. In addition, changes in allocation of phospholipid FA by mammary gland could be a reason for the cubic effect of treatments on C18:2 (n-6 cis) proportion of phospholipids. Supplementation of CSS linearly increased the proportion of UFA in milk phospholipids, suggesting that changes in the supply of UFA may have contributed to the alterations in the UFA concentration of milk phospholipids. This is in agreement with Lopez et al. (2008), who reported a more than 10 percentage point decrease of SFA in milk phospholipids following dietary supplementation of UFA. However, the proportion of SFA in milk phospholipids is associated with large variation. Lopez et al. (2008) and Menard et al.
(2010) detected more than $60 \%$ SFA in milk phospholipids from cows receiving a basal diet, whereas Fong et al. (2007) and Fauquant et al. (2005) report a proportion of SFA in milk phospholipids below $50 \%$. The discrepancies found in the literature may be explained by differences in the basal diet or, more likely, differences in the methods used to extract phospholipids from milk.

\section{FA Composition of Sphingomyelin}

The main FA of milk sphingomyelin were C16:0, C22:0, C23:0, and C24:0 in agreement with SanchezJuanes et al. (2009). The major effect of CSS supplementation on milk sphingomyelin composition was a quadratic effect in C22:0, which increased by almost 10 percentage points. In contrast, C23:0 proportion linearly decreased by 5 percentage points in cows receiving $15 \%$ CSS supplementation. The substitution of C23:0 with C22:0 in milk sphingomyelin probably reflects an increased availability of C22:0 in the mammary gland. Supplementation of CSS linearly decreased milk sphingomyelin proportion of C22:2 (n-6 cis), C20:5 (n-3 cis), and $\mathrm{C} 22: 1$ (n-9 cis), which resulted in a cubic response in proportion of UFA in milk sphingomyelin. This is in contrast to the effect of CSS supplementation on phospholipid composition, where CSS supplementation linearly increased the proportion of UFA. Therefore, the different FA composition in phospholipids and sphingomyelin may reflect the different synthesis pathway. In addition, CSS supplementation did not affect milk sphingomyelin proportion of C18:0, C16:0, or C18:2 (n-6, cis) in the present experiment. These findings reflect that the regulation of milk sphingomyelin secretion is not solely dependent on the dietary FA composition, but may involve the coordinated and highly regulated FA catabolism and synthesis in body tissues, in particular mammary glands (Christie, 1981; Bauchart, 1993). The cubic effect of CSS on sphingomyelin SFA could be due to the key role of saturated long-chain FA in maintaining rigidity of the MFGM. High proportion of SFA and high proportion of longchain FA $(>\mathrm{C} 20)$ of sphingomyelin are 2 properties that contribute to less fluidity and tend to support a structural role of sphingomyelin in maintaining rigidity of the MFGM (Bitman and Wood, 1990; Et-Thakafy et al., 2018). Our data show that the increase in SFA proportion in sphingomyelin was accompanied by a decrease in SFA proportion of phospholipids. Variation in the FA content of phospholipids from MFGM may be an adaptation to membrane fluidity requirements. Therefore, MFGM have more very-long-chain FA (more rigidity), compensated by more UFA (less rigidity). In addition, deposition, de novo synthesis, elongation, de- 
saturation, and mobilization of these FA in adipocytes (Halmemies-Beauchet-Filleau et al., 2013) may be a reason for the lack of CSS supplementation on sphingomyelin proportion of $\mathrm{C} 16: 0, \mathrm{C} 18: 0$, and $\mathrm{C} 18: 2$ (n-6 cis). The measured levels of the individual FA in the milk sphingomyelin are within the variations reported in the literature (Bitman and Wood, 1990; Noh and Koo, 2004; Fong et al., 2007). The changes in FA composition caused by dietary supplementation of CSS do not induce conformational changes in the sphingomyelin, as C22:0 and C23:0 are both long-chain SFA with similar physiological capacities. Thus, the potential to interact with cholesterol and form lipid rafts is most likely not affected.

\section{Mammary Transcription of Lipogenic Genes}

Mammary transcription of sphingolipogenic genes is activated at the onset of lactation (Bionaz and Loor, 2008), supporting that the synthesis of sphingomyelin is important for milk production. The SPTLC1 and SPTLC2 are considered rate-limiting factors in sphingomyelin synthesis, and decreased transcription indicates a decreased mammary de novo synthesis of sphingomyelin (Rabionet et al., 2014). This could be explained by a decreased demand for mammary sphingomyelin synthesis caused by a decreased demand for milk fat globule formation. Lopez et al. (2008) showed that milk fat globule size was decreased in cows receiving lipid supplements, which decrease the demand for membrane formation and sphingomyelin synthesis.

Although not significant, the more than $40 \%$ increase observed in $U G C G$ transcription after CSS supplementation may suggest that the mammary epithelial cells are directing newly synthesized ceramides to glucosphingolipid synthesis instead of sphingomyelin, which is the major sphingomyelin in bovine milk. The reason for this change may be due to a limited availability of choline for mammary sphingomyelin synthesis, and limited availability of choline may affect sphingomyelin synthesis (Lyman et al., 1975).

\section{CONCLUSIONS}

In summary, dietary supplementation of CSS increased the proportion of UFA in milk phospholipids. The SFA proportion of sphingomyelin increased with CSS supplementation. However, the UFA composition of milk sphingomyelin is regulated in a way that only allows minor structural changes to the sphingomyelin. Furthermore, mammary transcription of the gene coding for the rate-limiting enzyme in sphingomyelin de novo synthesis was decreased by CSS supplementation.

\section{ACKNOWLEDGMENTS}

This research was carried out in the project "Tailored milk and human health" funded by the Danish Ministry of Science, Technology and Innovation. The authors declare no conflict of interest.

\section{REFERENCES}

Aveldano, M. I., and L. A. Horrocks. 1983. Quantitative release of fatty acids from lipids by a simple hydrolysis procedure. J. Lipid Res. 24:1101-1105.

Bauchart, D. 1993. Lipid absorption and transport in ruminants. J. Dairy Sci. 76:3864-3881. https://doi.org/10.3168/jds.S0022 $-0302(93) 77728-0$

Bionaz, M., and J. J. Loor. 2008. Gene networks driving bovine milk fat synthesis during the lactation cycle. BMC Genomics 9:366. https://doi.org/10.1186/1471-2164-9-366.

Bitman, J., and D. L. Wood. 1990. Changes in milk-fat phospholipids during lactation. J. Dairy Sci. 73:1208-1216. https://doi.org/10 .3168/jds.S0022-0302(90)78784-X.

Cheng, K., M. H. Ropers, and C. Lopez. 2017. The miscibility of milk sphingomyelin and cholesterol is affected by temperature and surface pressure in mixed Langmuir monolayers. Food Chem. 224:114-123. https://doi.org/10.1016/j.foodchem.2016.12.035.

Christie, W. 1981. The effects of diet and other factors on the lipid composition of ruminant tissues and milk. Pages 193-226 in Lipid Metabolism in Ruminant Animals. Elsevier, Amsterdam, the Netherlands.

Eckhardt, E. R., D. Q. Wang, J. M. Donovan, and M. C. Carey. 2002. Dietary sphingomyelin suppresses intestinal cholesterol absorption by decreasing thermodynamic activity of cholesterol monomers. Gastroenterology 122:948-956. https://doi.org/10.1053/gast.2002 .32539 .

Et-Thakafy, O., N. Delorme, F. Guyomarc'h, and C. Lopez. 2018. Mechanical properties of milk sphingomyelin bilayer membranes in the gel phase: Effects of naturally complex heterogeneity, saturation and acyl chain length investigated on liposomes using AFM. Chem. Phys. Lipids 210:47-59. https://doi.org/10.1016/j .chemphyslip.2017.11.014.

Fauquant, C., V. R. Briard, N. Leconte, and M. C. Michalski. 2005. Differently sized native milk fat globules separated by microfiltration: Fatty acid composition of the milk fat globule membrane and triglyceride core. Eur. J. Lipid Sci. Technol. 107:80-86. https://doi .org/10.1002/ejlt.200401063.

Fong, B. Y., C. S. Norris, and A. K. H. MacGibbon. 2007. Protein and lipid composition of bovine milk-fat-globule membrane. Int. Dairy J. 17:275-288. https://doi.org/10.1016/j.idairyj.2006.05.004.

Halmemies-Beauchet-Filleau, A., P. Kairenius, S. Ahvenjärvi, V. Toivonen, P. Huhtanen, A. Vanhatalo, D. Givens, and K. Shingfield. 2013. Effect of forage conservation method on plasma lipids, mammary lipogenesis, and milk fatty acid composition in lactating cows fed diets containing a 60: 40 forage-to-concentrate ratio. J. Dairy Sci. 96:5267-5289. https://doi.org/10.3168/jds.2013-6571.

Hanada, K. 2003. Serine palmitoyltransferase, a key enzyme of sphingolipid metabolism. Biochim. Biophys. Acta 1632:16-30. https:// doi.org/10.1016/S1388-1981(03)00059-3.

Jenkins, G. M., and Y. Hannun. 1999. Sphingolipids as messengers of cell death. Pages 105-124 in Apoptosis: A Practical Approach. G. P. Studzinski, ed. Oxford University Press, Oxford, UK.

Jensen, S. K. 2008. Improved Bligh and Dyer extraction procedure. Lipid Technol. 20:280-281. https://doi.org/10.1002/lite.200800074.

Jiang, Y., S. K. Noh, and S. I. Koo. 2001. Egg phosphatidylcholine decreases the lymphatic absorption of cholesterol in rats. J. Nutr. 131:2358-2363. https://doi.org/10.1093/jn/131.9.2358.

Kaluzny, M. A., L. Duncan, M. Merritt, and D. Epps. 1985. Rapid separation of lipid classes in high-yield and purity using bonded phase columns. J. Lipid Res. 26:135-140. 
Kurtz, F. E. 1974. Page 125 in Fundamentals of Dairy Chemistry. B. R. Webb, A. H. Johnson, and J. A. Alford, ed. Aspen Publishers Inc., Westport, CT.

Lange, Y., and T. L. Steck. 2008. Cholesterol homeostasis and the escape tendency (activity) of plasma membrane cholesterol. Prog. Lipid Res. 47:319-332. https://doi.org/10.1016/j.plipres.2008.03 .001 .

Lopez, C. 2011. Milk fat globules enveloped by their biological membrane: unique colloidal assemblies with a specific composition and structure. Curr. Opin. Colloid Interface Sci. 16:391-404. https:// doi.org/10.1016/j.cocis.2011.05.007.

Lopez, C., M. Blot, V. Briard-Bion, C. Cirie, and B. Graulet. 2017. Butter serums and buttermilks as sources of bioactive lipids from the milk fat globule membrane: Differences in their lipid composition and potentialities of cow diet to increase n-3 PUFA. Food Res. Int. 100:864-872. https://doi.org/10.1016/j.foodres.2017.08.016.

Lopez, C., V. Briard-Bion, and O. Ménard. 2014. Polar lipids, sphingomyelin and long-chain unsaturated fatty acids from the milk fat globule membrane are increased in milks produced by cows fed fresh pasture based diet during spring. Food Res. Int. 58:59-68. https://doi.org/10.1016/j.foodres.2014.01.049.

Lopez, C., V. Briard-Bion, O. Ménard, E. Beaucher, F. Rousseau, J. Fauquant, N. Leconte, and B. Robert. 2011. Fat globules selected from whole milk according to their size: Different compositions and structure of the biomembrane, revealing sphingomyelin-rich domains. Food Chem. 125:355-368. https://doi.org/10.1016/j .foodchem.2010.09.005.

Lopez, C., V. Briard-Bion, O. Menard, F. Rousseau, P. Pradel, and J. M. Besle. 2008. Phospholipid, sphingolipid, and fatty acid compositions of the milk fat globule membrane are modified by diet. J. Agric. Food Chem. 56:5226-5236. https://doi.org/10.1021/ jf7036104.

Lopez, C., K. Cheng, and J. Perez. 2018. Thermotropic phase behavior of milk sphingomyelin and role of cholesterol in the formation of the liquid ordered phase examined using SR-XRD and DSC. Chem. Phys. Lipids 215:46-55. https://doi.org/10.1016/j .chemphyslip.2018.07.008.

Lopez, C., M. Madec, and R. Jimenez-Flores. 2010. Lipid rafts in the bovine milk fat globule membrane revealed by the lateral segregation of phospholipids and heterogeneous distribution of glycoproteins. Food Chem. 120:22-33. https://doi.org/10.1016/j.foodchem 2009.09.065

Lyman, R. L., C. Giotas, B. Medwadowski, and P. Miljanich. 1975. Effect of low methionine, choline deficient diets upon major unsaturated phosphatidyl choline fractions of rat liver and plasma. Lipids 10:157-167. https://doi.org/10.1007/BF02534154.

Malmsten, M., B. Bergenstahl, L. Nyberg, and G. Odham. 1994. Sphingomyelin from milk-Characterization of liquid-crystalline, liposome and emulsion properties. J. Am. Oil Chem. Soc. 71:10211026.

Menard, O., S. Ahmad, F. Rousseau, V. Briard-Bion, F. Gaucheron, and C. Lopez. 2010. Buffalo vs. cow milk fat globules: Size distribution, zeta-potential, compositions in total fatty acids and in polar lipids from the milk fat globule membrane. Food Chem. 120:544-551. https://doi.org/10.1016/j.foodchem.2009.10.053.

Noh, S. K., and S. I. Koo. 2004. Milk sphingomyelin is more effective than egg sphingomyelin in inhibiting intestinal absorption of cholesterol and fat in rats. J. Nutr. 134:2611-2616. https://doi.org/10 $.1093 /$ jn/134.10.2611.

Nyberg, L., R.-D. Duan, and Å. Nilsson. 2000. A mutual inhibitory effect on absorption of sphingomyelin and cholesterol. J. Nutr. Biochem. 11:244-249. https://doi.org/10.1016/S0955-2863(00)00069 $-3$.

Palmquist, D. L., and F. Schanbacher. 1991. Dietary fat composition influences fatty acid composition of milk fat globule membrane in lactating cows. Lipids 26:718-722. https://doi.org/10.1007/ BF02535620.

Rabionet, M., K. Gorgas, and R. Sandhoff. 2014. Ceramide synthesis in the epidermis. Biochim. Biophys. Acta 1841:422-434. https:// doi.org/10.1016/j.bbalip.2013.08.011.

Sanchez-Juanes, F., J. Alonso, L. Zancada, and P. Hueso. 2009. Distribution and fatty acid content of phospholipids from bovine milk and bovine milk fat globule membranes. Int. Dairy J. 19:273-278. https://doi.org/10.1016/j.idairyj.2008.11.006.

Slotte, J. P. 1999. Sphingomyelin-cholesterol interaction in biological and model membranes. Chem. Phys. Lipids 102:13-27. https://doi .org/10.1016/S0009-3084(99)00071-7.

Sorensen, M. T., J. V. Nørgaard, P. K. Theil, M. Vestergaard, and K. Sejrsen. 2006. Cell turnover and activity in mammary tissue during lactation and the dry period in dairy cows. J. Dairy Sci. 89:4632-4639. https://doi.org/10.3168/jds.S0022-0302(06)72513 -9 .

Spitsberg, V. L. 2005. Invited review: Bovine milk fat globule membrane as a potential nutraceutical. J. Dairy Sci. 88:2289-2294. https://doi.org/10.3168/jds.S0022-0302(05)72906-4.

Ward, R. E., J. B. German, and M. Corredig. 2006. Composition, applications, fractionation, technological and nutritional significance of milk fat globule membrane material. Pages 213-244 in Advanced Dairy Chemistry. Volume 2. Lipids. P. F. Fox and P. L. H. McSweeney, ed. Springer US, New York, NY.

Werner, L. B., L. Hellgren, M. Raff, S. Jensen, R. Petersen, T. Drachmann, and T. Tholstrup. 2011. Effect of dairy fat on plasma phytanic acid in healthy volunteers - A randomized controlled study. Lipids Health Dis. 10:95-107. https://doi.org/10.1186/1476-511X $-10-95$. 